Revistade
Economild
Contemporâned

\title{
TAXA DE CÂMBIO E AJUSTE EXTERNO: UMA INVESTIGAÇÃO COM MODELOS ARDL PARA AS ECONOMIAS EMERGENTES DO BRICS
}

\author{
Indiane Souza de Azevedo Queiroz ${ }^{a}$ \\ Flavio Vilela Vieira ${ }^{b}$ \\ àestre em Economia pelo Programa de Pós Graduação em Economia da Universidade Federal de \\ Uberlândia. Uberlândia, MG, Brasil.

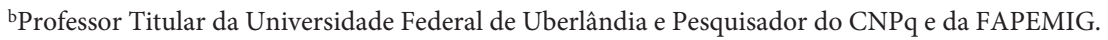 \\ Uberlândia, MG, Brasil. ORCID: https://orcid.org/0000-0001-9316-7990.
}

Artigo recebido em 29/05/2018 e aceito para publicação em 16/08/2019.

RESUMO: O objetivo deste trabalho é investigar o papel da taxa de câmbio (nível, desalinhamento e volatilidade) para o ajuste externo dos BRICS (1998 a 2015) usando modelos ARDL. Os resultados indicam uma grande assimetria no que diz respeito ao papel da taxa de câmbio no processo de ajustamento de longo e curto prazo. Para os modelos estimados com o desalinhamento da taxa de câmbio, esse se mostrou estatisticamente significativo para todas as economias, exceto a Índia. Já para os modelos utilizando a volatilidade cambial, apenas para o Brasil ocorreu significância para os dois modelos de ajuste de curto prazo. Finalmente, as maiores velocidades de ajustamento ocorreram nos modelos não lineares (NARDL).

PALAVRAS-CHAVE: taxa de câmbio; ajuste externo; BRICS; modelos ARDL.

CLASSIFICAÇÃO JEL: F32; C22; F41. 


\title{
EXCHANGE RATE AND EXTERNAL ADJUSTMENT: AN INVESTIGATION WITH ARDL MODELS FOR THE BRICS EMERGING ECONOMIES
}

\begin{abstract}
The objective of this work is to investigate the role of the exchange rate (level, misalignment and volatility) for the external adjustment of the BRICS (1998 to 2015) using ARDL models. The results indicate a strong asymmetry regarding the role of the exchange rate in the long and short-term adjustment process. For the models estimated with exchange rate misalignment, it was statistically significant for all economies except India, while for the models using exchange rate volatility, only for Brazil there was significance for the short-term adjustment in both models. Finally, the highest speed of adjustment were found in the NARDL model.
\end{abstract}

KEYWORDS: exchange rate; external adjustment; BRICS; ARDL models; N-ARD. 


\section{INTRODUÇÃO}

O debate acerca das questões relativas ao processo de ajuste externo sempre esteve presente nas discussões e estudos dos formuladores de políticas econômicas. Nos últimos anos, porém, este tema ganhou maior notoriedade devido aos persistentes desequilíbrios macroeconômicos nas principais economias mundiais. Tornou-se, então, necessário compreender quais são as principais causas, consequências e os mecanismos que tornaram esses desequilíbrios sustentáveis. Portanto, como forma a contribuir para o esclarecimento de questões relevantes sobre o comportamento das transações correntes, o objetivo deste trabalho consiste em realizar uma investigação empírica acerca da Conta de Transações Correntes para algumas das principais economias emergentes atuais (Brasil, Rússia, Índia, China e África do Sul), a fim de observar se a taxa de câmbio desempenhou um papel relevante no processo de ajuste externo, no período compreendido entre 1998 e 2015. Para tanto, será utilizado um modelo linear de cointegração auto regressivo de defasagem distribuída (ARDL) e outro modelo não-linear (N-ARDL), sendo o câmbio observado a partir de três conceitos, a saber: nível, volatilidade e desalinhamento. Parte-se de duas principais hipóteses. A primeira, mais elementar, consiste no fato de que a taxa de cambio desempenhou um papel importante para a promoção do ajuste externo nas economias emergentes selecionadas. A segunda hipótese pressupõe que a partir das variáveis macroeconômicas utilizadas no modelo abordado, há uma grande assimetria entre quais dessas variáveis foram, de fato, importantes para a promoção do ajuste externo nessas economias durante o período de estudo.

Os desequilíbrios consistem em grandes deficit e superavit das posições de conta corrente na economia global, de tal forma que desequilíbrios persistentes são vistos como financiamento contínuo do consumo negativo líquido das economias deficitárias pelas economias superavitárias (SADIKU, 2015). Ao abordar tal questão, Gourinchas (2012) vai além ao delimitar que estes desequilíbrios consistem no atual papel desempenhado pela economia americana de ser uma importadora líquida de capital, permitindo-se ser financiada por economias emergentes em rápido crescimento. Não há, porém, consenso de quais fatores são responsáveis pela manutenção desta posição corrente dos países.

A partir desta temática, o presente artigo está estruturado em mais quatro seções além desta introdução. Na primeira seção é apresentada uma revisão teórica e empírica acerca dos principais trabalhos que discutem essa temática, sob a ótica de distintas abordagens. Em seguida, na segunda seção, são apresentadas as descrições dos dados, além dos procedimentos metodológicos e a especificação dos modelos estimados. $\mathrm{Na}$ terceira seção apresentam-se os resultados obtidos e, por fim, na última seção são descritas as principais conclusões do trabalho. 


\section{REVISÃO DE LITERATURA}

\subsection{LITERATURA TEÓRICA}

A partir da década de 1980 começam a surgir os primeiros trabalhos com a preocupação em entender o saldo da Conta Corrente. Uma das primeiras abordagens a ganhar maior notoriedade consistiu na chamada Abordagem Intertemporal da Conta Corrente, inicialmente apresentada nos trabalhos de Obstelf e Rogoff (1995). Em suma, essa teoria nos mostra que a conta de transações correntes funciona como um amortecedor para suavizar o consumo frente a choques no fluxo de caixa nacional. Este fluxo de caixa consiste na renda nacional menos os investimentos e gastos do governo. Adotam-se as hipóteses de alta mobilidade de capital e de existência da teoria da renda permanente, considerando que a taxa de juros é exógena e que a paridade descoberta da taxa de juros se mantém (GHOSH, 1995).

Para essa abordagem, os países que esperam no longo prazo um aumento do fluxo de caixa nacional consideram ótimo contrair empréstimos hoje, provendo deficit nas transações correntes. Em contrapartida, se os países esperam que no longo prazo ocorra uma redução do fluxo de caixa nacional, é necessário gerar superavit hoje, para que, no futuro, o consumo seja condizente com a renda permanente esperada (OBSTFELD, 2005; GHOSH, 1995). Ao abordar tal teoria, Loayza (1999) destaca que uma das principais contribuições desta vertente consistiu no fato de delimitar que o impacto das mudanças econômicas no balanço de Conta Corrente pode variar de acordo com sua origem, persistência e tempo. Por outro lado, Gourinchas (2013) ressalta que essa vertente teórica se põe como um avanço teórico, porém, sob a perspectiva empírica, ainda não se apresenta como um consenso, dado que a mesma produz resultados mistos e suas previsões foram muitas vezes rejeitadas por diversos autores em seus estudos.

A partir do final da década de 1990, demais autores começaram a se preocupar com as questões relativas a conta corrente e começaram a investigar quais fatores foram responsáveis por promover as alterações significativas que passaram a ocorrer com maior frequência. Dentre essas, a abordagem que ganhou maior relevância consistiu na hipótese da Superabundância de Poupança Global. De acordo com Bernanke (2005), os crescentes deficit americanos são consequência de um problema de excesso de poupança, resultado de políticas praticadas pelos países em desenvolvimento que promoveram um aumento da oferta de poupança global. A partir dessas políticas estes países obtiveram superavit em suas contas correntes, que proporcionou, em última instância, que se tornassem financiadores líquidos nos mercados financeiros globais. 
Kregel (2010), ao descrever questões relativas as causas dos desequilíbrios globais, concorda parcialmente com Bernanke (2005), principalmente no que se refere ao fato de que estes desequilíbrios foram resultado de políticas externas dos países em desenvolvimento basicamente orientadas para exportações. Porém, o autor destaca um fator importante: a crescente mobilidade dos fluxos de capitais. Sobretudo, observa-se que estas políticas baseadas em exportações são consequência da incapacidade dos países em desenvolvimento de transformar o seu crescimento baseado em exportações em crescimento baseado na demanda interna.

Dooley (2003) observa os desequilíbrios a partir da vertente conhecida como hipótese Bretton Woods II. Para o autor, o sistema monetário-financeiro internacional revive o sistema Bretton Woods. Antes, nas décadas de 1950 e 1960, tinha-se uma periferia representada por Europa e Japão e um centro representado por Estados Unidos. Após o colapso deste sistema, houve um período de transição, no qual nenhum país adotou/optou por ter, enquanto objetivo de política econômica, uma estratégia de desenvolvimento. Porém, a partir da década de 1990, a Ásia, por meio de políticas de acumulação de reservas, controle de fluxos de capitais e movimentações cambiais começou a adotar esta estratégia e, dessa forma, foi elevada à periferia mundial tendo como regiões centrais agora os Estados Unidos e a Europa.

Sob uma ótica distinta, Bibow (2010) acredita que os desequilíbrios de conta corrente foram resultado de políticas fáceis praticadas pelo banco central americano, devido a dois fatores. O primeiro refere-se às políticas macroeconômicas expansionistas que promoveram, na sua visão, redução das taxas de juros. O segundo fator consiste no fato do banco americano ter funcionado como um intermediador financeiro, emitindo títulos nacionais, o que permitiu coletar o excesso de recursos acumulados nas economias em desenvolvimento e investir em títulos da dívida americana. Estas políticas ocasionaram alta liquidez global. Essa alta liquidez promoveu um excesso de dólar nos mercados globais durante os anos de 2003 a 2007. No momento em que esse excesso de dólar se tornou escassez, apresentou-se o principal mecanismo de transmissão da crise financeira global de 2008.

Gourinchas (2012) vai de encontro com Bibow (2010) no que tange a existir uma conexão entre os desequilíbrios globais e a crise financeira de 2008, dado que são vistos como produto de causas comuns, dentre elas, as políticas econômicas adotadas e as distorções no mercado de crédito. Porém, Bibow (2010) vai além em sua análise. Para o autor, apesar da conta corrente fornecer um importante sinal de alerta, essa não captura os riscos financeiros ou stress dos mercados. Os países europeus consistem em um bom exemplo, dado que, apesar destes países apresentarem uma conta corrente "equilibrada”, sofreram fortemente com a crise financeira. É necessário, portanto, observar para além dos desequilíbrios da conta corrente, os desequilíbrios globais de 
liquidez que medem a diferença entre o passivo externo em vencimento e o valor garantido dos ativos externos (GOURINCHAS, 2012).

Em oposição a essa visão, Borio (2016) destaca que existe um grande problema em relação ao que os formuladores de políticas hoje entendem por ser a Conta Corrente. Para o autor, é um erro tratar "desequilíbrios globais" e "desequilíbrios de conta corrente" como sinônimos, além de delimitar que a conta corrente não funciona como um preditor de crises. Os melhores indicadores para prever as crises financeiras consistem nos booms de créditos. Dessa forma, o grande problema hoje do Sistema Monetário Financeiro Internacional consiste não na capacidade de restringir o tamanho e a persistência dos desequilíbrios de Conta Corrente, mais sim na incapacidade de restringir os desequilíbrios financeiros.

Flassbeck (2018), ao observar os crescentes desequilíbrios globais argumenta que os fluxos financeiros especulativos são os grandes responsáveis por não se obter sucesso com os mecanismos de ajustes internacionais, o que acarreta uma maior fragilidade financeira no sistema global. Em oposição aos teóricos que abordam que os desequilíbrios globais são uma consequência natural das economias cada vez mais integradas, o autor acredita que uma maior abertura dos fluxos de capitais não consiste em uma alternativa viável para redução dos desequilíbrios, dada a existência do movimento denominado de "carry trade". Basicamente, esse consiste em operações financeiras de empréstimos e venda da moeda com baixo rendimento para empréstimos e venda da moeda com alto rendimento. Mudanças na taxa de câmbio entre o momento de compra e venda, portanto, podem proporcionar ganhos ou implicar em perdas monetárias, baseados nas expectativas de diferencial de taxa de juros. O grande problema é que as políticas nacionais destinadas a combater a inflação por meio de aumento nas taxas de juros podem acabar por fornecer fortes incentivos a esse tipo de especulação. Nessa situação, apresenta-se uma não efetividade da política monetária nacional, levando a uma maior fragilidade financeira e a custos reais no que tange a um esforço de ajustes da economia nacional ao sistema econômico global. Portanto, segundo Flassbeck (2018), ao contrário do que se pensa na teoria tradicional de que a volatilidade cambial tende a reduzir as formas de especulação, ocorre justamente o contrário. É necessário, principalmente nas economias em desenvolvimento com mercado de capitais abertos, haver uma menor volatilidade cambial a fim de não proporcionar ameaças aos investimentos de longo prazo. Os regimes cambiais "intermediários" devem ser preferidos em detrimento do regime cambial fixo ou livremente flutuante por oferecer maior espaço para ajuste da taxa de câmbio e conter a instabilidade dos mercados financeiros internacionais.

Por fim, estudando a conta corrente das economias emergentes, cabe destacar a abordagem desenvolvida por intelectuais na América Latina, mais especificadamente, no 
Brasil, denominada novo-desenvolvimentismo (BRESSER-PEREIRA, 2011; BRESSERPEREIRA, OREIRO e MARCONI, 2016). Esses autores consideram que a taxa de câmbio consiste em um preço macroeconômico que flutua em torno do seu equilíbrio corrente. No caso das economias em desenvolvimento, a taxa de câmbio não flutua em torno de um equilíbrio corrente por haver uma tendência à sobreapreciação crônica. Dessa forma, há uma alteração na estrutura produtiva dos países, dado que esses acabam por financiar seus deficit em conta corrente via aumento das exportações de recursos naturais. Como essa forma de financiamento não aumenta a poupança interna, esses países são obrigados a recorrer a poupança externa. O grande problema é que de acordo Bresser-Pereira e Gala (2007) a poupança externa não promove crescimento econômico. Em outras palavras, o influxo de poupança que esses países recebem não geram crescimento da taxa de investimento e, dessa forma, apenas proporcionam um aumento do consumo e do endividamento externo. Basicamente, esse aumento de consumo ocorre porque com a taxa de cambio apreciada há aumento do rendimento do trabalho e do capital em termos reais, implicando em redução do lucro do empresário. Portanto, temos por um lado as empresas desestimuladas a investir e por outro os trabalhadores e rentistas estimulados a consumir (BRESSER-PEREIRA, 2007; BRESSER-PEREIRA e GALA, 2007; BRESSER-PEREIRA e NAKANO, 2003).

Fernando Cardim Carvalho (2018) ao analisar o chamado "novo desenvolvimentismo" e como essa vertente teórica entende o papel da taxa de câmbio no desenvolvimento econômico, argumenta que para esses autores a taxa de câmbio de equilíbrio é responsável por estabelecer uma posição "natural” no sistema, porém, ao se analisar muito o viés comercial das relações, acaba-se por subestimar o papel dos fluxos financeiros nessa relação. Isso porque para os teóricos desenvolvimentistas a necessidade de se estabelecer um maior controle dos fluxos de capitais fica em segundo plano, controlando apenas os fluxos financeiros de entrada, devido a um maior impacto na sobrevalorização da moeda. Em oposição, Carvalho (2018) defende uma maior necessidade de se observar as variáveis financeiras autônomas, visto que um controle dos fluxos de capitais perpassa por uma observação maior em relação aos fluxos de saída, no qual se consegue evitar um movimento severo de fuga de capitais, que acarreta a iminência de crises no balanço de pagamentos.

\subsection{LITERATURA EMPÍRICA}

Após realizar uma síntese das principais vertentes teóricas acerca da Conta de Transações Correntes, cabe identificarmos alguns trabalhos que se preocuparam em investigar empiricamente esse processo. Busca-se destacar alguns trabalhos que apresentam uma preocupação de examinar o papel no câmbio no processo de ajuste externo. 
Incialmente, Loayza (1999) buscou observar a relação empírica entre o deficit em Conta Corrente e um amplo conjunto de variáveis macroeconômica para um grupo de 44 economias em desenvolvimento, no período compreendido entre 1966 e 1995. Para atingir tal objetivo, o autor fez uso de um modelo com dados em painel, a partir do Método dos Momentos Generalizados (GMM). Os principais resultados sugerem que existe um nível moderado de persistência nos deficit da balança de transações correntes para além do que pode ser explicado pelo comportamento dos seus determinantes. Em relação à taxa de crescimento, percebe-se que seu aumento nos países industrializados contribui para reduzir os deficit em Conta Corrente dos países em desenvolvimento. Este processo se dá principalmente pelo aumento da demanda de exportações. Por fim, uma apreciação da taxa de câmbio real, um agravamento dos termos de troca e uma redução nas taxas de juros internacionais proporcionam um aumento no deficit em Conta Corrente.

Chinn (2003) investigou quais são os determinantes de médio prazo para a conta corrente utilizando uma abordagem que destaca os determinantes do saldo da poupança e investimento de longo prazo. O período de estudo compreende os anos de 1971 a 1995 e utilizam um conjunto de 18 países industrializados e 71 países em desenvolvimento. As estimações foram realizadas a partir de dados em cross-section, por meio da estimação de um modelo MQO. Os resultados sugerem que nos países em desenvolvimento, o saldo orçamental do governo, as posições líquidas de ativos, o aprofundamento financeiro e uma maior volatilidade dos termos de troca estão correlacionados positivamente com os saldos em conta corrente. O grau de abertura ao comércio internacional está fracamente associado a maiores deficit em Conta Corrente e os indicadores de controles de capital e crescimento médio do PIB têm pouca relação sistemática com os saldos de Conta Corrente.

Lee (2006) observou a dinâmica da conta corrente e da taxa de câmbio, utilizando uma das implicações da abordagem intertemporal da Conta Corrente, na qual choques temporários não têm efeito no longo prazo sobre a taxa de câmbio real. Utiliza-se um modelo de Vetores Autorregressivos (VAR) e analisam-se as economias pertencentes ao grupo G7 no período de estudo (1979 a 200), a saber: Estados Unidos, Canadá, Reino Unido, Japão, Alemanha, França e Itália. Dentre os resultados mais importantes, destaca-se a delimitação de que choques temporários desempenham um papel maior na explicação da variação da conta corrente, enquanto choques permanentes desempenham um papel maior na explicação da variação do câmbio para todas as economias, exceto Estados Unidos. Para esse país, a deterioração da conta corrente se deve a fatores permanentes e as variações do câmbio se devem a choques temporários. Em suma, há uma assimetria do comportamento da taxa de câmbio real americana em relação ao comportamento das outras economias pertencentes ao G7 no período de estudo. 
Gruber (2007) investigou o comportamento dos deficit em conta corrente americano e o superavit dos países asiáticos. Para tanto, aborda-se que apenas utilizando variáveis macroeconômicas é impossível capturar todos os efeitos decorrentes da Conta Corrente, sendo necessário, portanto, introduzir uma variável de crise financeira e duas medidas de atratividade de capital, a saber: qualidade institucional e desenvolvimento financeiro. O estudo é realizado para um conjunto de 61 países entre o período de 1982 a 2003. Foram realizadas diversas regressões com dados em cross-section e em painel. Dentre os principais resultados obtidos, destaca-se que as crises estão sistematicamente associadas a desequilíbrios mais acentuados da conta corrente e que as crises da década de 1990, especialmente nos países da Ásia Oriental, contribuíram significativamente para a geração dos desequilíbrios macroeconômicos atuais.

Lane (2012) analisou o processo contínuo dos Desequilíbrios Globais em 65 economias avançadas e emergentes durante o período de 1969 a 2008, a partir de uma regressão em dados de painel. Adota-se a hipótese de que estes desequilíbrios pré-crise aumentaram além dos níveis consistentes com as posições sustentáveis de médio prazo. Os resultados obtidos no estudo sugerem que, em termos de mecanismo de ajuste, no caso dos países que experimentaram melhorias mais significativas nos saldos de Conta Corrente, estes obtiveram declínios mais acentuados na produção e na demanda doméstica. Já para os países deficitários, o principal canal de ajustamento consistiu na compressão das despesas, e o mecanismo de ajustamento cambial desempenhou um papel relativamente modesto no ajuste externo após a crise financeira.

Brissimis (2012) buscou estudar para o caso da Grécia, os fatores macroeconômicos, financeiros e estruturais que moldaram a evolução da balança de transações correntes durante o período compreendido entre 1960 e 2007. Em sua análise, os autores utilizaram um teste de cointegração FMOLS e, dentre os principais resultados obtidos, destaca-se que a apreciação cambial e maior volatilidade da inflação influenciam negativamente a conta corrente. A poupança doméstica financia parcialmente o investimento privado, rejeitando a hipótese tida na literatura de Feldstein-Horioka. O principal fator que contribuiu para a deterioração da conta corrente pós 1999 consistiu na diminuição significativa das taxas de poupança privadas.

Sadiku (2015) investigou uma relação empírica entre a conta corrente e alguns indicadores econômicos através de um modelo de Cointegração ARDL, para o período compreendido entre os anos de 1998 e 2013. O país de estudo consiste na República da Macedônia (Fyrom). Dentre os principais resultados, ressalta-se uma forte relação de cointegração entre o saldo em conta corrente, o equilíbrio fiscal, o desenvolvimento financeiro, os termos de troca e o grau de abertura. Há existência de uma relação de longo prazo entre as variáveis, de tal forma que após qualquer choque, levam-se dois 
períodos para que a balança da conta corrente retorne ao seu nível de equilíbrio de longo prazo. Apresenta-se também que a evolução da conta corrente é fortemente determinada pela evolução do saldo passado.

Martin (2016) buscou averiguar empiricamente se os regimes cambiais afetam o ajuste da conta corrente. Em suma, o autor buscou investigar a validação da hipótese desenvolvida por Friedman (1953), na qual delimita que as taxas de câmbio nominais produzem movimentos corretivos de tal forma a evitar que grandes desajustes e crises se desenvolvam. Para tanto, realizou-se uma análise em painel desequilibrado, para um conjunto de 180 países, compreendendo os anos de 1960-2007. Dentre os principais resultados obtidos, tem-se que os regimes de taxa de câmbio flutuante consistentemente proporcionam uma reversão média mais rápida da conta corrente entre os países não industrializados. Para os regimes de câmbio fixo, apresentam-se maiores desequilíbrios de conta corrente, sendo mais propensos a sofrer reversões abruptas e onerosas.

\section{PROCEDIMENTOS METODOLÓGICOS E RESULTADOS}

Antes da descrição das variáveis e estimações dos modelos, e dado o objetivo de analisar o papel da taxa de câmbio (nível, desalinhamento e volatilidade) para as transações correntes, faz-se necessário uma breve sistematização dos regimes cambiais dos países dos BRICS no período de 1998 a 2015, correspondente ao de estimação dos modelos ARDL. A Tabela A1 do Apêndice sistematiza a evolução da classificação coarse dos regimes cambiais dos BRICS com base em Ilzetski, Reinhart e Rogoff (2019).

A análise da evolução das classificações dos regimes cambiais indica uma predominância de regimes cambiais rígido (2) e intermediário (3) para os BRICS de 1998 a 2015. As exceções são China, com regime fixo de 1998 a 2005, Brasil, com regime flexível em 1999 quando da mudança do regime cambial em janeiro de 1999, e Rússia em 1998 e 2015 com regime cambial mais flexível.

Existem vários estudos sobre o comportamento/trajetória da taxa de câmbio e dos regimes cambiais nos BRICS - ver Das (2019) para a China; Couto e Meurer (2017) e Nassif et al. (2015) para o Brasil; Pattnaik et al. (2003) para a Índia; Basher et al. (2016) e Mironov e Petronevich (2015) para a Rússia; e Aron (2014) para a África do Sul. De forma mais geral os autores indicam uma preocupação de que tais economias possam vivenciar fenômenos como a Doença Holandesa e um processo de desindustrialização, especialmente nos casos de Brasil, Rússia e África do Sul, que têm alta concentração na exportação de bens primários/recursos naturais. Além disso, a preocupação dessas economias emergentes em geral está em evitar períodos de apreciação duradoura da 
taxa de câmbio, dado que isso implica em problemas nas contas externas (transações correntes) e em geral estão associadas aos impactos negativos na taxa de crescimento. ${ }^{1}$

A amostra de países selecionados consiste nas economias pertencentes ao grupo BRICS (Brasil, China, Índia, Rússia e África do Sul). Essas são as principais economias emergentes mundiais. Os dados apresentam periodicidade trimestral e referem-se aos anos de 1998 a 2015. As descrições das variáveis utilizadas no modelo são apresentadas abaixo: ${ }^{2}$

\section{Quadro 1 - Variáveis, descrição e fonte de dados}

\begin{tabular}{|c|c|c|}
\hline Variável & Descrição & Fonte de Dados \\
\hline $\begin{array}{l}\text { Saldo de Transações } \\
\text { Correntes (BTC) }\end{array}$ & $\begin{array}{l}\text { Saldo das Transações Correntes como } \\
\text { porcentagem do PIB. }\end{array}$ & $\begin{array}{l}\text { Internacional Financial } \\
\text { Statistics }\end{array}$ \\
\hline $\begin{array}{l}\text { Taxa de Câmbio Real } \\
\text { Efetiva (TCREF) }\end{array}$ & $\begin{array}{l}\text { Consiste em um índice que leva em consideração } \\
\text { as médias ponderadas das taxas de câmbio } \\
\text { bilaterais de cada país, ajustadas pelo índice de } \\
\text { preços ao consumidor relativos aos seus principais } \\
\text { parceiros comercias. Índice } 2010=100 .\end{array}$ & $\begin{array}{l}\text { Bank for Internacional } \\
\text { Settlements }\end{array}$ \\
\hline $\begin{array}{l}\text { Desalinhamento Cambial } \\
\text { (DESAL) }\end{array}$ & $\begin{array}{l}\text { Obtido a partir do Filtro Hodrick-Prescott - HP } \\
\text { (Componente Cíclico). }\end{array}$ & $\begin{array}{l}\text { Bank for Internacional } \\
\text { Settlements }\end{array}$ \\
\hline $\begin{array}{l}\text { Volatilidade Cambial } \\
\text { (VOLAT_TCREF) }\end{array}$ & $\begin{array}{l}\text { Obtido a partir da estimação de modelos Auto } \\
\text { regressivos de Heterocedasticidade Condicional } \\
\text { ARCH-GARCH. }\end{array}$ & $\begin{array}{l}\text { Bank for Internacional } \\
\text { Settlements }\end{array}$ \\
\hline $\begin{array}{l}\text { Ativos Externos Líquidos } \\
\text { (NFA) }\end{array}$ & $\begin{array}{l}\text { Consiste na diferença entre estoque total de ativos } \\
\text { e o estoque total de passivos como } \% \text { do PIB. }\end{array}$ & $\begin{array}{l}\text { Internacional Financial } \\
\text { Statistics }\end{array}$ \\
\hline $\begin{array}{l}\text { Volatilidade dos Termos de } \\
\text { Troca (VOLAT_TT) }\end{array}$ & $\begin{array}{l}\text { Consiste na razão entre o preço das exportações e } \\
\text { importações de cada país. A partir desta medida, } \\
\text { foi estimado a volatilidade por meio de modelos } \\
\text { ARCH-GARCH. }\end{array}$ & Global Economics Monitor \\
\hline Grau de Abertura (XPIB) & $\begin{array}{l}\text { É o volume de exportações mais importações, } \\
\text { como porcentagem do PIB. }\end{array}$ & $\begin{array}{l}\text { Internacional Financial } \\
\text { Statistics }\end{array}$ \\
\hline $\begin{array}{l}\text { Desenvolvimento } \\
\text { Financeiro (DESENF) }\end{array}$ & $\begin{array}{l}\text { É a razão entre o agregado monetário (M2) e o } \\
\text { PIB. }\end{array}$ & $\begin{array}{l}\text { Internacional Financial } \\
\text { Statistics para dados de } \\
\text { Brasil, China, Rússia e Africa } \\
\text { do Sul; } \\
\text { World Bank, para Índia }\end{array}$ \\
\hline
\end{tabular}

Fonte: Elaboração própria.

1 Recentemente se desenvolveu uma literatura empírica sobre os efeitos da taxa de câmbio sobre o crescimento. Ver Rodrik (2008) e Vieira e MacDonald (2012).

2 Outras variáveis de controle como taxa de dependência e taxa de poupança não foram inseridas na análise empírica devido a indisponibilidade de encontrar dados trimestrais. 
A abordagem desenvolvida neste trabalho consiste no modelo Autorregressivos de Defasagens Distribuídas (ARDL). Este modelo foi inicialmente apresentado nos trabalhos de Pesaran e Shin (1998) e Pesaran, Shin e Smith (2001). O processo de estimação divide-se basicamente em dois momentos. Primeiro, busca-se confirmar a existência dos vetores de longo prazo, e sequencialmente, se confirmado, segue-se para a estimação dos respectivos coeficientes de longo prazo das variáveis. Em um segundo momento, estima-se a velocidade de ajustamento ao equilíbrio de longo prazo, representada por coeficiente ECM (-1) e obtêm-se os coeficientes de curto prazo das variáveis. O modelo geral estimado na forma de vetores de correção de erros (ARDL-ECM) para uma variável dependente e uma explicativa é especificado como segue:

$$
\Delta y_{t}=\alpha_{0}+\alpha_{1} t+\delta_{1} y_{t-1}+\delta_{2} x_{t-1}+\sum_{i=0}^{n} \varphi_{1 i} \Delta y_{t-i}+\sum_{i=0}^{n} \varphi_{2 i} \Delta x_{t-i}+\varepsilon_{t}
$$

Para a definição dos coeficientes de cointegração, Pesaran e Shin (2001) desenvolveram o Boundstesting Approach, abordagem que permite encontrar a valor da estatística F. A partir dela, tem-se os valores críticos (limites) para I(0) bounds e I(1) bounds. Se o valor da estatística F estiver acima destes limites, é possível inferir que há cointegração entre as variáveis. Se o valor da estatística F estiver abaixo destes limites, é possível concluir que não há cointegração. Por fim, se o valor da estatística F estiver entre os limites estabelecidos (bounds), não é possível inferir nenhum tipo de conclusão, sendo os resultados, portanto, inconclusivos. Já em relação a definição da velocidade de ajustamento ao equilíbrio, os coeficientes ECM (-1) devem ser negativos e estatisticamente significativos.

Em relação à outros métodos de cointegração convencional, a abordagem ARDL apresenta algumas vantagens, visto que permite utilizar os dados independente dos regressores serem estacionários $\mathrm{I}(0)$, não estacionários $\mathrm{I}(1)$ ou mutuamente cointegrados, além de melhor capturar as relações de longo prazo para pequenas amostras de dados, e de capturar as relações de curto e longo prazo simultaneamente.

Inicialmente são estimados dois modelos ARDL. No primeiro, opta-se por estimar a taxa de câmbio real efetiva juntamente com o desalinhamento cambial, para além das variáveis de controle macroeconômicas utilizadas. No segundo modelo, é realizada a substituição da variável desalinhamento cambial pela variável volatilidade cambial. Os modelos estimados são apresentados abaixo: 
- Modelo ARDL - Modelo 1

$$
\begin{gathered}
\Delta(\text { BTC })_{t}=\mu+\alpha_{1} t+\beta_{1}(\text { BTC })_{t-1}+\beta_{2}(\text { TCREF })_{t-1}+\beta_{3}(\text { DESAL })_{t-1}+\beta_{4}(N F A)_{t-1}+\beta_{5}(\text { XPIB })_{t-1}+ \\
\beta_{6}(\text { DESENF })_{t-1}+\beta_{7}(\text { VOLAT_TT })_{t-1}+\sum_{i=1}^{p} \beta_{8} \Delta(\text { BTC })_{t-i}+\sum_{i=1}^{q} \beta_{9} \Delta(\text { TCREF })_{t-i}+ \\
\sum_{i=1}^{r} \beta_{10} \Delta(\text { DESAL })_{t-i}+\sum_{i=1}^{s} \beta_{11} \Delta(N F A)_{t-i}+\sum_{i=1}^{m} \beta_{12} \Delta(\text { XPIB })_{t-i}+\sum_{i=1}^{f} \beta_{13} \Delta(\text { DESENF })_{t-i}+ \\
\sum_{i=1}^{d} \beta_{14} \Delta(\text { VOLAT_TT })_{t-i}+u_{t}
\end{gathered}
$$

- Modelo ARDL - Modelo 2

$$
\begin{aligned}
\Delta(\text { BTC })_{t}= & \mu+\alpha_{1} t+\beta_{1}(\text { BTC })_{t-1}+\beta_{2}(\text { TCREF })_{t-1}+\beta_{3}(\text { VOLAT_TCREF })_{t-1}+\beta_{4}(N F A)_{t-1}+ \\
& \beta_{5}(\text { XPIB })_{t-1}+\beta_{6}(\text { DESENF })_{t-1}+\beta_{7}(\text { VOLAT_TT })_{t-1}+\sum_{i=1}^{p} \beta_{8} \Delta(\text { BTC })_{t-i}+ \\
& \sum_{i=1}^{q} \beta_{9} \Delta(\text { TCREF })_{t-i}+\sum_{i=1}^{r} \beta_{10} \Delta(\text { VOLAT_TCREF })_{t-i}+\sum_{i=1}^{s} \beta_{11} \Delta(N F A)_{t-i}+ \\
& \sum_{i=1}^{m} \beta_{12} \Delta(\text { XPIB })_{t-i}+\sum_{i=1}^{f} \beta_{13} \Delta(\text { DESENF })_{t-i}+\sum_{i=1}^{d} \beta_{14} \Delta(\text { VOLAT_TT })_{t-i}+v_{t}
\end{aligned}
$$

Em seguida, estimam-se mais dois modelos, agora ambos N-ARDL. Baseado em Shin (2014), neste modelo, substitui-se a variável taxa de câmbio real efetiva (TCREF) pelas variáveis apreciação cambial e depreciação cambial. O processo de geração destas variáveis está apresentado abaixo. Discriminam-se as variações positivas (apreciação - APREC) e as variações negativas (depreciação - DEPREC) da taxa de câmbio real efetiva:

$$
\begin{gathered}
\text { APREC }=\sum_{j=1}^{t} \Delta\left(\text { TCREF }_{t}^{+}\right)_{t}=\sum_{j=1}^{t} \max \left(\text { TCREF }_{j}, 0\right) \\
\text { DEPREC }=\sum_{j=1}^{t} \Delta\left(\text { TCREF }_{t}^{-}\right)_{t}=\sum_{j=1}^{t} \min \left(\text { TCREF }_{j}, 0\right)
\end{gathered}
$$

Após a delimitação dessas variáveis, estão definidos o terceiro e quarto modelos. No terceiro, estimam-se a apreciação e a depreciação cambial juntamente com o desalinhamento. No quarto, substitui-se, novamente, a variável desalinhamento cambial por volatilidade cambial. A forma final dos modelos está apresentada abaixo: 
- Modelo N-ARDL - Modelo 3

$$
\begin{gathered}
\Delta(\text { BTC })_{t}=\mu+\alpha_{1} t+\beta_{1}(\text { BTC })_{t-1}+\beta_{2}(\text { APREC })_{t-1}+\beta_{3}(\text { DEPREC })_{t-1}+\beta_{4}(D E S A L)_{t-1} \\
+\beta_{5}(N F A)_{t-1}+\beta_{6}(\text { XPIB })_{t-1}+\beta_{7}(D E S E N F)_{t-1}+\beta_{8}(\text { VOLAT_TT })_{t-1}+ \\
\sum_{i=1}^{p} \beta_{9} \Delta(\text { BTC })_{t-i}+\sum_{i=1}^{q} \beta_{10} \Delta(\text { APREC })_{t-i}+\sum_{i=1}^{r} \beta_{11} \Delta(D E P R E C)_{t-i}+\sum_{i=1}^{s} \beta_{12} \Delta(D E S A L)_{t-i}+ \\
\sum_{i=1}^{m} \beta_{13} \Delta(N F A)_{t-i}+\sum_{i=1}^{f} \beta_{14} \Delta(\text { XPIB })_{t-i}+\sum_{i=1}^{d} \beta_{15} \Delta(D E S E N F)_{t-i}+\sum_{i=1}^{d} \beta_{16} \Delta(\text { VOLAT_TT })_{t-i}+e_{t}
\end{gathered}
$$

\section{- Modelo N-ARDL - Modelo 4}

$$
\begin{gathered}
\Delta(\text { BTC })_{t}=\mu+\alpha_{1} t+\beta_{1}(\text { BTC })_{t-1}+\beta_{2}(\text { APREC })_{t-1}+\beta_{3}(\text { DEPREC })_{t-1}+\beta_{4}(\text { VOLAT_TCREF })_{t-1}+ \\
\beta_{5}(\text { NFA })_{t-1}+\beta_{6}(\text { XPIB })_{t-1}+\beta_{7}(\text { DESENF })_{t-1}+\beta_{8}(\text { VOLAT_TT })_{t-1}+\sum_{i=1}^{p} \beta_{9} \Delta(\text { BTC })_{t-i}+ \\
\sum_{i=1}^{q} \beta_{10} \Delta(\text { APREC })_{t-i}+\sum_{i=1}^{r} \beta_{11} \Delta(\text { DEPREC })_{t-i}+\sum_{i=1}^{s} \beta_{12} \Delta(\text { VOLAT_TCREF })_{t-i}+\sum_{i=1}^{m} \beta_{13} \Delta(N F A)_{t-i}+ \\
\sum_{i=1}^{f} \beta_{14} \Delta(\text { XPIB })_{t-i}+\sum_{i=1}^{d} \beta_{15} \Delta(\text { DESENF })_{t-i}+\sum_{i=1}^{d} \beta_{16} \Delta(\text { VOLAT_TT })_{t-i}+w_{t}
\end{gathered}
$$

Inicialmente se faz necessário conhecer a ordem de integração das variáveis apresentadas no modelo. Em suma, para ser possível a aplicação da modelagem

\begin{tabular}{|c|c|c|c|c|c|c|}
\hline \multirow{2}{*}{ Variáveis } & \multirow{2}{*}{ País } & \multicolumn{4}{|c|}{ Testes } & \multirow{2}{*}{ Decisão } \\
\hline & & $\mathrm{ADF}$ & KPSS & PP & DF-GLS & \\
\hline \multirow{5}{*}{ BTC } & Brasil & $-1,98$ & 0,24 & $-2,62$ & $-1,77$ & $\mathrm{I}(\mathrm{I})$ \\
\hline & China & $-1,63$ & 0,20 & $-1,97$ & $-1,55$ & $\mathrm{I}(\mathrm{I})$ \\
\hline & Índia & $-4,08^{\star *}$ & 0,42 & $-3,97^{* *}$ & $-3,12^{\star *}$ & $\mathrm{I}(0)$ \\
\hline & Rússia & $-3,18^{*}$ & $0,51^{\star}$ & $-3,14^{*}$ & $-1,63$ & $\mathrm{I}(\mathrm{I})$ \\
\hline & África & $-2,12$ & $0,62^{*}$ & $-3,14^{*}$ & $-1,45$ & $\mathrm{I}(\mathrm{I})$ \\
\hline \multirow{5}{*}{ XPIB } & Brasil & $-3,13^{*}$ & 0,20 & $-3,17^{\star}$ & $-0,80$ & $\mathrm{I}(\mathrm{I})$ \\
\hline & China & $-1,62$ & 0,27 & $-1,75$ & $-1,04$ & $\mathrm{I}(\mathrm{I})$ \\
\hline & Índia & $-3,08^{\star *}$ & 0,23 & $-3,03^{* *}$ & $-2,89^{* *}$ & $\mathrm{I}(0)$ \\
\hline & Rússia & $-7,38^{\star *}$ & 0,07 & $7,38^{* *}$ & $-1,70$ & $\mathrm{I}(\mathrm{I})$ \\
\hline & África & $-3,15^{*}$ & $0,75^{* *}$ & $-2,72^{*}$ & $-1,95^{*}$ & $\mathrm{I}(\mathrm{I})$ \\
\hline
\end{tabular}
ARDL/N-ARDL é necessário que variáveis integradas de ordem (0) e ordem (1) estejam presentes no modelo. Os resultados estão apresentados na Tabela 1. Foram realizados quatro testes de raiz unitária: Argumented Dickey-Fuller (AFD); Kwiatkowski - Phillips-Schmidt - Shin (KPSS); Phillips Perron (PP) e Modified Dickey-Fuller (DF-GLS). Verifica-se a existência de variáveis integradas tanto de ordem (0) quanto de ordem (1), o que justifica a utilização desses modelos.

Tabela 1 - Testes de raiz unitária 
Tabela 1 - Testes de raiz unitária

(Cont.)

\begin{tabular}{|c|c|c|c|c|c|c|}
\hline \multirow{2}{*}{ Variáveis } & \multirow{2}{*}{ País } & \multicolumn{4}{|c|}{ Testes } & \multirow{2}{*}{ Decisão } \\
\hline & & ADF & KPSS & PP & DF-GLS & \\
\hline \multirow{5}{*}{ NFA } & Brasil & 0,35 & $1,05^{\star *}$ & 0,08 & 0,94 & $\mathrm{I}(\mathrm{I})$ \\
\hline & China & $-0,91$ & $1,07^{* *}$ & 0,27 & $-0,60$ & $\mathrm{I}(\mathrm{I})$ \\
\hline & Índia & $-0,39$ & $1,08^{\star *}$ & $-0,44$ & 1,16 & $\mathrm{I}(\mathrm{I})$ \\
\hline & Rússia & $-0,91$ & $1,05^{\star *}$ & $-0,91$ & 0,36 & $\mathrm{I}(\mathrm{I})$ \\
\hline & África & $-1,41$ & $1,08^{\star *}$ & $-1,44$ & 0,37 & $\mathrm{I}(\mathrm{I})$ \\
\hline \multirow{5}{*}{ DESENF } & Brasil & $-2,02$ & $0,32^{* *}$ & $-2,11$ & $-0,39$ & $\mathrm{I}(\mathrm{I})$ \\
\hline & China & $-0,21$ & $0,96^{\star *}$ & $-4,65^{* *}$ & 1,39 & $\mathrm{I}(\mathrm{I})$ \\
\hline & Índia & $-1,63$ & $0,64^{*}$ & $-1,62$ & $-1,34$ & $\mathrm{I}(\mathrm{I})$ \\
\hline & Rússia & $-0,24$ & $1,06^{* *}$ & $-0,57$ & $-0,32$ & $\mathrm{I}(\mathrm{I})$ \\
\hline & África & $-1,43$ & $0,49^{*}$ & $-1,45$ & $-0,84$ & $\mathrm{I}(\mathrm{I})$ \\
\hline \multirow{5}{*}{ VOLAT_TT } & Brasil & $-10,9^{* *}$ & 0,21 & $-11,0^{* *}$ & $-9,10^{\star *}$ & $\mathrm{I}(0)$ \\
\hline & China & $-5,43^{* *}$ & 0,17 & $-5,50^{* *}$ & $-5,12^{* *}$ & $\mathrm{I}(0)$ \\
\hline & Índia & $-4,08$ & 0,25 & $-7,72^{* *}$ & $-3,93^{* *}$ & $\mathrm{I}(0)$ \\
\hline & Rússia & $-9,90^{* *}$ & 0,34 & $-32,34^{* *}$ & $-1,56$ & $\mathrm{I}(0)$ \\
\hline & África & $-3,10^{* *}$ & 0,26 & $-11,10$ & $-2,96^{\star *}$ & $\mathrm{I}(0)$ \\
\hline \multirow{5}{*}{ TCREF } & Brasil & -1.95 & $0,51^{*}$ & $-1,71$ & $-1,22$ & $\mathrm{I}(\mathrm{I})$ \\
\hline & China & 0,97 & $0,72^{*}$ & 0,96 & $-0,04$ & $\mathrm{I}(\mathrm{I})$ \\
\hline & Índia & $-3,70^{* *}$ & 0,34 & $-2,67^{\star}$ & $-3,68^{* *}$ & $\mathrm{I}(0)$ \\
\hline & Rússia & $-1,31$ & $0,81^{\star \star}$ & $-1,45$ & $-1,24$ & $\mathrm{I}(\mathrm{I})$ \\
\hline & África & $-2,33^{*}$ & 0,14 & $-2,48^{*}$ & $-0,79$ & $\mathrm{I}(\mathrm{I})$ \\
\hline \multirow{5}{*}{ VOLAT_TCREF } & Brasill & $-8,27^{* *}$ & 0,21 & $-8,29 * *$ & $-8,00^{* *}$ & $\mathrm{I}(0)$ \\
\hline & China & $-8,72$ & $0,57^{\star}$ & $-8,79^{* *}$ & $-6,33^{\star *}$ & $\mathrm{I}(0)$ \\
\hline & Índia & $-10,22^{* *}$ & 0,05 & $-10,09^{* *}$ & $-4,21^{* *}$ & $\mathrm{I}(0)$ \\
\hline & Rússia & $-8,68^{* *}$ & 0,14 & $-8,68^{* *}$ & $-8,53^{* *}$ & $\mathrm{I}(0)$ \\
\hline & África & $-9,09^{* *}$ & 0,08 & $-9,07^{* *}$ & $-8,97^{\star *}$ & $\mathrm{I}(0)$ \\
\hline \multirow{5}{*}{ DESAL } & Brasil & $-5,89^{* *}$ & 0,03 & $-3,57^{* *}$ & $-5,43^{* *}$ & $\mathrm{I}(0)$ \\
\hline & China & $-5,65^{\star *}$ & 0,03 & $-3,52^{* *}$ & $-4,25^{\star *}$ & $\mathrm{I}(0)$ \\
\hline & Índia & $-4,81^{* *}$ & 0,02 & $-3,83^{* *}$ & $-2,71^{\star *}$ & $\mathrm{I}(0)$ \\
\hline & Rússia & $-4,31^{* *}$ & 0,09 & $-4,39$ & $-1,99^{*}$ & $\mathrm{I}(0)$ \\
\hline & África & $-3,85^{* *}$ & 0,03 & $-4,01^{* *}$ & $-3,24^{* *}$ & $\mathrm{I}(0)$ \\
\hline
\end{tabular}

Fonte: Elaboração própria.

Em seguida são estimados os quatros modelos ARDL/N-ARDL apresentados na seção (3). Os dois primeiros consistem nos modelos ARDL. Em ambos, foram utilizadas três defasagens para cada um dos cinco países. Para o terceiro modelo, utilizam-se três defasagens para todos os países, exceto para a China, visto a necessidade de utilização de quatro defasagens. No quarto modelo são utilizadas três defasagens para cada país. Para todos os quatro modelos, o critério de seleção consiste no Critério Bayesianos de Akaike (AIC). A ordem das variáveis e os resultados são apresentados nas Tabelas 2 e 3 abaixo. Nessa, apresentam-se ainda os resultados do 
teste de Autocorrelação Breusch-Godfrey ou teste Lagrange Multiplier (LM). Para este teste, a hipótese nula consiste na inexistência de correlação serial nos resíduos. Faz-se necessária, portanto, a não rejeição da hipótese nula.

Tabela 2 - ARDL: variável dependente BTC

\begin{tabular}{lcccc}
\hline & \multicolumn{2}{c}{ Modelo 1 } & \multicolumn{2}{c}{ Modelo 2 } \\
\cline { 2 - 5 } País & Modelo ARDL & $\begin{array}{c}\text { Teste LM Auto Corr. } \\
(\text { Prob })\end{array}$ & Modelo ARDL & $\begin{array}{c}\text { Teste LM Auto Corr. } \\
\text { (Prob) }\end{array}$ \\
\hline Brasil & $(3,3,3,2,1,2,3)^{1}$ & $4,947(0,2927)$ & $(3,3,3,3,3,2,3)^{1}$ & $0,212(0,6449)$ \\
China & $(3,1,1,0,2,0,0)^{3}$ & $7,231(0,1242)$ & $(3,0,1,0,2,0,0)^{3}$ & $7,667(0,1045)$ \\
Índia & $(1,0,0,1,3,1,0)^{3}$ & $2,089(0,7194)$ & $(1,0,0,1,3,1,0)^{3}$ & $1,311(0,8586)$ \\
Rússia & $(3,3,3,1,0,3,0)^{3}$ & $6,681(0,1537)$ & $(1,2,1,0,1,0,1)^{3}$ & $8,752(0,0676)$ \\
África & $(2,2,3,3,1,0,1)^{1}$ & $2,526(0,112)$ & $(2,2,0,0,1,1,1)^{3}$ & $3,520(0,172)$ \\
\hline
\end{tabular}

Nota: 1 = constante e tendência; 2 = com constante e nenhuma tendência; $3=$ sem constante e nenhuma tendência Modelo 1 - ordem das variáveis: Balança de Transações Correntes, Desalinhamento Cambial, Ativos Externos Líquidos, Grau de Abertura, Desenvolvimento Financeiro e Volatilidade dos termos de troca. Modelo 2 - ordem das variáveis: Balança de Transações Correntes, Volatilidade cambial, Ativos externos líquidos, Grau de Abertura, Desenvolvimento financeiro e Volatilidade dos termos de troca.

Fonte: Elaboração própria.

Tabela 3 - NARDL: variável dependente BTC

\begin{tabular}{lcccc}
\hline \multirow{2}{*}{ País } & \multicolumn{2}{c}{ Modelo 3 } & \multicolumn{2}{c}{ Modelo 4 } \\
\cline { 2 - 5 } & Modelo N-ARDL & $\begin{array}{c}\text { Teste LM Auto Corr. } \\
\text { (Prob) }\end{array}$ & Modelo N-ARDL & $\begin{array}{c}\text { Teste LM Auto Corr. } \\
\text { (Prob) }\end{array}$ \\
\hline Brasil & $(3,0,0,1,3,3,3,3)^{1}$ & $4,680(0,3217)$ & $(3,0,1,3,2,3,2,3)^{1}$ & $0,547(0,4592)$ \\
China & $(4,0,3,4,0,2,0,0)^{3}$ & $3,529(0,1712)$ & $(3,3,0,3,0,2,0,2)^{3}$ & $5,056(0,0798)$ \\
Índia & $(1,2,1,1,1,3,1,0)^{3}$ & $0,692(0,9522)$ & $(1,0,1,0,1,3,3,0)^{3}$ & $2,331(0,6750)$ \\
Rússia & $(3,3,3,3,2,3,3,0)^{1}$ & $6,339(0,1752)$ & $(1,2,1,0,0,1,0,1)^{3}$ & $8,636(0,0708)$ \\
África & $(2,3,2,2,2,3,0,3)^{3}$ & $7,356(0,1182)$ & $(2,3,0,0,2,1,3,3)^{3}$ & $5,631(0,2284)$ \\
\hline
\end{tabular}

Nota: $1=$ constante e tendência; $2=$ com constante e nenhuma tendência; $3=$ sem constante e nenhuma tendência. Modelo 3 - ordem das variáveis: Balança de Transações Correntes, Desalinhamento Cambial, Ativos Externos Líquidos, Grau de Abertura, Desenvolvimento Financeiro e Volatilidade dos termos de troca. Modelo 4 - ordem das variáveis: Balança de Transações Correntes, Volatilidade cambial, Ativos externos líquidos, Grau de Abertura, Desenvolvimento financeiro e Volatilidade dos termos de troca.

Fonte: Elaboração própria.

O próximo passo consiste em examinar a existência de vetores de cointegração entre as variáveis. O teste utilizado consiste no ARDL Bounds Testing Approach, já descrito no início desta seção. Os resultados para os quatro modelos estão apresentados nas Tabelas 4 e 5. Tanto para Brasil quanto para a Índia, em ambos 
modelos estimados, verifica-se a presença de cointegração aos níveis de significância de $10 \%$ e $5 \%$.

Para China, no modelo 1, que levam em consideração o desalinhamento cambial, há cointegração ao nível de significância de $10 \%$, sendo os resultados inconclusivos ao nível de significância de 5\%. Em relação ao modelo 2, que se apresenta a volatilidade do câmbio, os resultados são inconclusivos tanto aos níveis de significância de $10 \%$ quanto ao nível de 5\%. Para o modelo 3 há cointegração para todos os níveis e, finalmente, para o modelo 4 os resultados são inconclusivos aos níveis de significância de $10 \%$ e $5 \%$.

Para a Rússia, no modelo 1, os resultados são inconclusivos para os níveis de significância de $10 \%$ e $5 \%$, e em contrapartida, apresentam cointegração nos modelos 2 e 4 para ambos os níveis estatísticos. Para o modelo 3 há cointegração ao nível de significância de $10 \%$ e resultados inconclusivos ao nível de significância de 5\%. Por fim, para a África do Sul, no modelo 1, tem-se resultados inconclusivos aos níveis de significância de $10 \%$ e $5 \%$, e para os modelos 2 , 3 e 4 há cointegração ao nível de significância de $10 \%$ e resultados inconclusivos ao nível de significância de $5 \%$.

Tabela 4 - Teste de cointegração (ARDL bounds testing approach)

\begin{tabular}{|c|c|c|c|c|c|c|c|}
\hline \multirow{3}{*}{ País } & & \multirow{3}{*}{$\begin{array}{l}\text { Estatística } \\
\text { F }\end{array}$} & \multicolumn{4}{|c|}{ ValoresCríticos } & \multirow{3}{*}{$\begin{array}{l}\text { Cointegração de } \\
\text { Longo Prazo }\end{array}$} \\
\hline & & & \multicolumn{2}{|c|}{ I(0) Bound } & \multicolumn{2}{|c|}{ I(1) Bound } & \\
\hline & & & $10 \%$ & $5 \%$ & $10 \%$ & $5 \%$ & \\
\hline \multirow{2}{*}{ Brasil } & Modelo 1 & 4,32 & 2,33 & 2,63 & 3,25 & 3,62 & Sim \\
\hline & Modelo 2 & 3,92 & 2,33 & 2,63 & 3,25 & 3,62 & Sim \\
\hline \multirow{2}{*}{ China } & Modelo 1 & 3,14 & 1,75 & 2,04 & 2,87 & 3,24 & $\begin{array}{c}\text { Sim, Inconclusivo } \\
\text { a } 5 \%\end{array}$ \\
\hline & Modelo 2 & 1,76 & 1,75 & 2,04 & 2,87 & 3,24 & $\begin{array}{l}\text { Inconclusivo para } \\
10 \text { e } 5 \%\end{array}$ \\
\hline \multirow{2}{*}{ Índia } & Modelo 1 & 5,08 & 1,75 & 2,04 & 2,87 & 3,24 & Sim \\
\hline & Modelo 2 & 5,17 & 1,75 & 2,04 & 2,87 & 3,24 & Sim \\
\hline \multirow[t]{2}{*}{ Rússia } & Modelo 1 & 1,79 & 1,75 & 2,04 & 2,04 & 3,24 & $\begin{array}{c}\text { Inconclusivo a } 10 \mathrm{e} \\
5 \%\end{array}$ \\
\hline & Modelo 2 & 3,94 & 1,75 & 2,04 & 2,87 & 3,24 & Sim \\
\hline \multirow{2}{*}{ África } & Modelo 1 & 3,16 & 2,33 & 2,63 & 3,25 & 3,62 & $\begin{array}{c}\text { Inconclusivo a } 10 \mathrm{e} \\
5 \%\end{array}$ \\
\hline & Modelo 2 & 2,08 & 1,75 & 2,04 & 2,87 & 3,24 & $\begin{array}{c}\text { Sim, Inconclusivo } \backslash \\
5 \%\end{array}$ \\
\hline
\end{tabular}

Nota: Ho - não há cointegração no longo prazo.

Fonte: Elaboração própria. 
Tabela 5 - Teste de cointegração (ARDL bounds testing approach)

\begin{tabular}{|c|c|c|c|c|c|c|c|}
\hline \multirow{3}{*}{ País } & & \multirow{3}{*}{ Estatística F } & \multicolumn{4}{|c|}{ Valores Críticos } & \multirow[t]{3}{*}{$\begin{array}{c}\text { Cointegração de Longo } \\
\text { Prazo }\end{array}$} \\
\hline & & & \multicolumn{2}{|c|}{$\mathrm{I}(0)$ Bound } & \multicolumn{2}{|c|}{ I(1) Bound } & \\
\hline & & & $10 \%$ & $5 \%$ & $10 \%$ & $5 \%$ & \\
\hline \multirow{2}{*}{ Brasil } & Modelo 3 & 4,45 & 2,22 & 2,5 & 3,17 & 3,5 & Sim \\
\hline & Modelo 4 & 3,63 & 2,22 & 2,5 & 3,17 & 3,5 & Sim \\
\hline \multirow{2}{*}{ China } & Modelo 3 & 3,53 & 1,7 & 1,97 & 2,83 & 3,18 & Sim \\
\hline & Modelo 4 & 1,98 & 1,7 & 1,97 & 2,83 & 3,18 & Inconclusiva a 10 e $5 \%$ \\
\hline \multirow{2}{*}{ Índia } & Modelo 3 & 5,90 & 1,7 & 1,97 & 2,83 & 3,18 & Sim \\
\hline & Modelo 4 & 3,71 & 1,7 & 1,97 & 2,83 & 3,18 & Sim \\
\hline \multirow{2}{*}{ Rússia } & Modelo 3 & 3,33 & 2,22 & 2,5 & 3,17 & 3,5 & Sim, Inconclusivo a $5 \%$ \\
\hline & Modelo 4 & 4,47 & 1,7 & 1,97 & 2,83 & 3,18 & Sim \\
\hline \multirow{2}{*}{ África } & Modelo 3 & 3,16 & 1,7 & 1,97 & 2,83 & 3,18 & Sim, Inconclusivo a $5 \%$ \\
\hline & Modelo 4 & 2,41 & 1,7 & 1,97 & 2,83 & 3,18 & Sim, Inconclusivo a 5\% \\
\hline
\end{tabular}

Nota: Ho - não há cointegração no longo prazo.

Fonte: Elaboração própria.

Subsequentemente à verificação da existência dos vetores de longo prazo, são estimados os coeficientes de equilíbrio de longo prazo para todos modelos. Em suma, os resultados não corroboram a hipótese inicial, segundo a qual a taxa de câmbio desempenha um papel importante para a promoção do ajuste externo em todos os membros do grupo BRICS. Apenas para a Índia a taxa de câmbio apresentou significância em todos os quatro modelos. Já em relação à segunda hipótese, em que há uma grande assimetria entre quais são as variáveis mais importantes no processo de ajuste externo de cada país, os resultados a corroboram. De fato, há uma diferença significativa para cada uma das economias em desenvolvimento no período de estudo (1998-2015). Em detalhes, nas Tabelas 6, 7, 8 e 9 a seguir, os resultados e os coeficientes são descritos de forma discriminada para cada país

Tabela 6 - ARDL: modelo 1, coeficientes de longo prazo

\begin{tabular}{lccccc}
\hline & Brasil & China & Índia & Rússia & África \\
\hline Variáveis & $\begin{array}{c}\text { Coeficiente } \\
(\text { Prob })\end{array}$ & $\begin{array}{c}\text { Coeficiente } \\
(\text { Prob })\end{array}$ & $\begin{array}{c}\text { Coeficiente } \\
(\text { Prob })\end{array}$ & $\begin{array}{c}\text { Coeficiente } \\
(\text { Prob })\end{array}$ & $\begin{array}{c}\text { Coeficiente } \\
\text { (Prob) }\end{array}$ \\
\hline \multirow{2}{*}{ TCREF } & $-0,001$ & $-0,000$ & $-0,0006$ & $-0,0004$ & 0,0018 \\
& $(0,3287)$ & $(0,9004)$ & $(0,0488)$ & $(0,7932)$ & $(0,0323)$ \\
DESAL & 0,000 & 0,000 & $-0,000$ & $-0,0041$ & $-0,000$ \\
& $(0,9652)$ & $(0,7212)$ & $(0,5408)$ & $(0,1268)$ & $(0,2278)$ \\
NFA & $-0,000$ & $-0,000$ & $-0,000$ & $-0,0002$ & $-0,0000$ \\
& $(0,0005)$ & $(0,2450)$ & $(0,7371)$ & $(0,0573)$ & $(0,0557)$ \\
\hline
\end{tabular}


Tabela 6 - ARDL: modelo 1, coeficientes de longo prazo

(Cont.)

\begin{tabular}{lccccc}
\hline & Brasil & China & Índia & Rússia & África \\
\hline Variáveis & $\begin{array}{c}\text { Coeficiente } \\
(\text { Prob })\end{array}$ & $\begin{array}{c}\text { Coeficiente } \\
(\text { Prob })\end{array}$ & $\begin{array}{c}\text { Coeficiente } \\
(\text { Prob) }\end{array}$ & $\begin{array}{c}\text { Coeficiente } \\
(\text { Prob })\end{array}$ & $\begin{array}{c}\text { Coeficiente } \\
(\text { Prob) }\end{array}$ \\
\hline XPIB & 0,4421 & 0,2573 & $-0,1358$ & 0,0809 & $-0,101$ \\
& $(0,0198)$ & $(0,0000)$ & $(0,3377)$ & $(0,3725)$ & $(0,4764)$ \\
DESENF & 0,339 & $-0,0118$ & 0,0249 & 0,1334 & $-0,0456$ \\
VOLAT_ & $(0,0387)$ & $(0,3288)$ & $(0,0198)$ & $(0,3480)$ & $(0,171)$ \\
TT & 0,864 & $-0,053$ & $-0,424$ & 0,000 & $-0,0712$ \\
@TREND & $(0,1866)$ & $(0,3206)$ & $(0,0051)$ & $(0,9453)$ & $(0,0828)$ \\
\hline
\end{tabular}

Fonte: Elaboração própria.

Tabela 7 - ARDL: modelo 2, coeficientes de longo prazo

\begin{tabular}{lccccc}
\hline & Brasil & China & Índia & Rússia & África \\
\hline Variáveis & $\begin{array}{c}\text { Coeficiente } \\
(\text { Prob })\end{array}$ & $\begin{array}{c}\text { Coeficiente } \\
\text { (Prob) }\end{array}$ & $\begin{array}{c}\text { Coeficiente } \\
(\text { Prob })\end{array}$ & $\begin{array}{c}\text { Coeficiente } \\
\text { (Prob) }\end{array}$ & $\begin{array}{c}\text { Coeficiente } \\
\text { (Prob) }\end{array}$ \\
\hline TCREF & $-0,0009$ & 0,000 & $-0,0007$ & $-0,0006$ & $-0,0004$ \\
& $(0,2559)$ & $(0,6210)$ & $(0,0204)$ & $(0,4568)$ & $(0,4389)$ \\
VOLAT_TCREF & 4,312 & 0,4135 & 0,365 & 2,778 & 2,646 \\
& $(0,0432)$ & $(0,3652)$ & $(0,8871)$ & $(0,4962)$ & $(0,3363)$ \\
NFA & $-0,000$ & 0,000 & 0,000 & $-0,000$ & $-0,000$ \\
& $(0,0008)$ & $(0,2079)$ & $(0,6741)$ & $(0,5804)$ & $(0,2544)$ \\
XPIB & 0,2933 & 0,343 & $-0,119$ & 0,3186 & $-0,1682$ \\
& $(0,227)$ & $(0,0001)$ & $(0,3913)$ & $(0,0003)$ & $(0,5919)$ \\
DESENF & 0,1659 & $-0,028$ & 0,0250 & $-0,0035$ & 0,104 \\
& $(0,0407)$ & $(0,0960)$ & $(0,0201)$ & $(0,9547)$ & $(0,4808)$ \\
VOLAT_TT & 0,3048 & $-0,125$ & $-0,429$ & $-0,000$ & $-0,185$ \\
@TREND & $(0,5942)$ & $(0,1420)$ & $(0,0049)$ & $(0,1322)$ & $(0,286)$ \\
\hline
\end{tabular}

Fonte: Elaboração própria.

Tabela 8 - N-ARDL: modelo 3, coeficientes de longo prazo

\begin{tabular}{lccccc}
\hline & Brasil & China & Índia & Rússia & África \\
\hline Variáveis & $\begin{array}{c}\text { Coeficiente } \\
(\text { Prob })\end{array}$ & $\begin{array}{c}\text { Coeficiente } \\
(\text { Prob })\end{array}$ & $\begin{array}{c}\text { Coeficiente } \\
(\text { Prob })\end{array}$ & $\begin{array}{c}\text { Coeficiente } \\
(\text { Prob })\end{array}$ & $\begin{array}{c}\text { Coeficiente } \\
(\text { Prob) }\end{array}$ \\
\hline \multirow{2}{*}{ APREC } & $-0,0005$ & 0,000 & $-0,0010$ & 0,0031 & 0,0008 \\
& $(0,3319)$ & $(0,4998)$ & $(0,0022)$ & $(0,0851)$ & $(0,003)$ \\
DEPREC & $-0,0005$ & $-0,000$ & $-0,0007$ & 0,0035 & 0,0006 \\
& $(0,3792)$ & $(0,3569)$ & $(0,0195)$ & $(0,0724)$ & $(0,0013)$ \\
DESAL & $-0,0005$ & $-0,0002$ & 0,0013 & $-0,001$ & $-0,0016$ \\
& $(0,3144)$ & $(0,4253)$ & $(0,3102)$ & $(0,0813)$ & $(0,0052)$ \\
\hline
\end{tabular}


Tabela 8 - N-ARDL: modelo 3, coeficientes de longo prazo

(Cont.)

\begin{tabular}{lccccc}
\hline & Brasil & China & Índia & Rússia & África \\
\hline Variáveis & $\begin{array}{c}\text { Coeficiente } \\
(\text { Prob })\end{array}$ & $\begin{array}{c}\text { Coeficiente } \\
(\text { Prob })\end{array}$ & $\begin{array}{c}\text { Coeficiente } \\
(\text { Prob })\end{array}$ & $\begin{array}{c}\text { Coeficiente } \\
(\text { Prob })\end{array}$ & $\begin{array}{c}\text { Coeficiente } \\
\text { (Prob) }\end{array}$ \\
\hline NFA & $-0,000$ & $-0,000$ & 0,0000 & $-0,000068$ & $-0,000$ \\
& $(0,0001)$ & $(0,5960)$ & $(0,5968)$ & $(0,5301)$ & $(0,1004)$ \\
XPIB & 0,5925 & 0,3838 & $-0,004$ & 0,432 & $-0,241$ \\
& $(0,0035)$ & $(0,0000)$ & $(0,9770)$ & $(0,0002)$ & $(0,0707)$ \\
DESENF & 0,1794 & $-0,022$ & 0,017 & $-0,551$ & $-0,0856$ \\
& $(0,0238)$ & $(0,0884)$ & $(0,679)$ & $(0,0008)$ & $(0,0037)$ \\
VOLAT_TT & 0,520 & $-0,090$ & $-0,2929$ & 0,000 & $-0,1084$ \\
& $(0,3529)$ & $(0,1373)$ & $(0,0177)$ & $(0,1081)$ & $(0,0057)$ \\
@TREND & 0,0036 & & & 0,0089 & - \\
\hline
\end{tabular}

Fonte: Elaboração própria.

Tabela 9 - N-ARDL: modelo 4, coeficientes de longo prazo

\begin{tabular}{lccccc}
\hline & Brasil & China & Índia & Rússia & África \\
\hline Variáveis & $\begin{array}{c}\text { Coeficiente } \\
(\text { Prob })\end{array}$ & $\begin{array}{c}\text { Coeficiente } \\
(\text { Prob })\end{array}$ & $\begin{array}{c}\text { Coeficiente } \\
(\text { Prob })\end{array}$ & $\begin{array}{c}\text { Coeficiente } \\
(\text { Prob })\end{array}$ & $\begin{array}{c}\text { Coeficiente } \\
(\text { Prob) }\end{array}$ \\
\hline APREC & $-0,002$ & 0,00006 & $-0,0007$ & $-0,001$ & $-0,0001$ \\
& $(0,5584)$ & $(0,4580)$ & $(0,0157)$ & $(0,2809)$ & $(0,3401)$ \\
DEPREC & $-0,0004$ & $-0,000$ & $-0,0006$ & $-0,0004$ & $-0,0002$ \\
& $(0,4692)$ & $(0,8287)$ & $(0,0493)$ & $(0,6084)$ & $(0,2100)$ \\
VOLAT_TCREF & 0,9309 & $-0,6007$ & $-0,300$ & $-1,502$ & 0,1038 \\
& $(0,1635)$ & $(0,6727)$ & $(0,9298)$ & $(0,6252)$ & $(0,7605)$ \\
NFA & $-0,000$ & 0,000 & 0,000 & $-0,00001$ & $-0,0000$ \\
& $(0,0090)$ & $(0,3754)$ & $(0,4861)$ & $(0,2658)$ & $(0,0236)$ \\
XPIB & 0,6336 & 0,4213 & $-0,167$ & 0,3022 & 0,0417 \\
& $(0,0006)$ & $(0,0005)$ & $(0,2571)$ & $(0,0008)$ & $(0,6920)$ \\
DESENF & 0,0950 & $-0,0323$ & 0,028 & 0,031 & 0,0214 \\
& $(0,1052)$ & $(0,0971)$ & $(0,0177)$ & $(0,6233)$ & $(0,6178)$ \\
VOLAT_TT & 0,9314 & $-0,1487$ & $-0,352$ & $-0,000$ & $-0,122$ \\
@TREND & $(0,0895)$ & $(0,2065)$ & $(0,0166)$ & $(0,1158)$ & $(0,0528)$ \\
\hline
\end{tabular}

Fonte: Elaboração própria.

- Brasil: Nos modelos 1 e 3, que levam em consideração o desalinhamento cambial, não há diferença no que tange os resultados dos modelos ARDL e N-ARDL. Em ambos, o desalinhamento se mostrou não significativo. Ainda para esses dois modelos, as variáveis estatisticamente significativas são: ativos externos líquidos (negativamente), grau de abertura (positivamente) e o desenvolvimento financeiro (positivamente). Em contrapartida, ao observarmos os modelos 2 e 4, 
que levam em consideração a volatilidade do câmbio, houve alterações significativas em relação aos modelos ARDL e N-ARDL, dado que somente para o modelo ARDL (2) a volatilidade se apresenta significativa. Ainda em relação a este modelo, as variáveis responsáveis pela determinação das transações correntes foram, além da volatilidade do câmbio (positivamente), os ativos externos líquidos (negativamente) e o desenvolvimento financeiro (positivamente). Já em relação ao modelo 4 (N-ARDL), as variáveis significativas foram: ativos externos líquidos (negativamente), grau de abertura (positivamente) e volatilidade dos termos de troca (positivamente). Apenas ativos externos líquidos apresentaram-se significativos para todos os quatros modelos.

- China: Para o modelo 1, apenas a variável grau de abertura (positivamente) se mostrou significativa. Para o modelo 3, as variáveis que se mostraram significativas foram ativos externos líquidos (negativamente), grau de abertura (positivamente) e desenvolvimento financeiro (positivamente). Nos modelos 2 e 4, que levam em consideração a volatilidade da taxa de câmbio, não há diferenças em relação aos resultados dos modelos ARDL e N-ARDL. Para ambos, apenas o grau de abertura (positivamente) e o desenvolvimento financeiro (negativamente) foram significativos. Cabe ressaltar que, para os quatros modelos, o grau de abertura se apresentou relevante para explicar alterações na conta corrente. Esse resultado só reitera a importância do comércio internacional para o desempenho da economia chinesa.

- Índia: Para todos os quatro modelos, o câmbio desempenha um papel importante no processo de determinação da conta corrente. De forma discriminada, para os modelos que levam em consideração o desalinhamento cambial, no modelo 1 (ARDL), a taxa de câmbio (negativamente), o desenvolvimento financeiro (positivamente) e volatilidade dos termos de troca (negativamente) são as variáveis significativas e, no modelo 3 (N-ARDL), tanto a apreciação (negativamente) quanto a depreciação (negativamente) são determinantes da conta corrente, além da volatilidade dos termos de troca (negativamente). Já para os modelos com a volatilidade do câmbio, tanto no modelo 2 (ARDL) quanto no modelo 4 (N-ARDL), o desenvolvimento financeiro (positivamente) e a volatilidade dos termos de troca (negativamente) são determinantes de longo prazo da Conta Corrente. A distinção entre eles está no fato de que, para o modelo 2 (ARDL), a taxa de câmbio em nível (negativamente) se apresenta significativa e para os modelos 4 (N-ARDL) a significância se apresenta na apreciação (negativamente) e depreciação (negativamente) do câmbio. 
- Rússia: Para os modelos que utilizam o desalinhamento cambial, no modelo 1 , apenas os ativos externos líquidos (negativamente) foram significativos. No modelo 3, (N-ARDL), o grau de abertura (positivamente) e o desenvolvimento financeiro (negativamente) são responsáveis por variações na conta corrente. Ainda de acordo com este modelo, a apreciação (positivamente), depreciação (positivamente) e desalinhamento cambial (negativamente) apresentaram significância ao nível de $10 \%$. Em relação aos modelos que apresentam a volatilidade nas suas equações, tanto para o modelo 2 (ARDL) quanto para o modelo 4 (N-ARDL), a única variável que se mostrou significativa para a determinação da conta corrente foi o grau de abertura (positivamente).

- África do Sul: Nos modelos 1 e 3, que apresentam na equação a variável desalinhamento cambial, tem-se que, para o modelo 1 (ARDL), as variáveis taxa de câmbio real efetiva (positivamente), ativos externos líquidos (negativamente) e a volatilidade dos termos de troca (negativamente) foram responsáveis por explicar variações na conta corrente. Em oposição, no modelo 3 (N-ARDL), todas as variáveis foram significativas, a saber: apreciação (positivamente), depreciação (positivamente), ativos externos líquidos (negativamente), desalinhamento (negativamente), grau de abertura (negativamente), desenvolvimento financeiro (negativamente) e a volatilidade dos termos de troca (negativamente). Em relação aos modelos 2 e 4, que levam em consideração a volatilidade do câmbio, para o modelo 2 (ARDL) nenhuma variável apresentou significância. No modelo 4 (N-ARDL), apenas os ativos externos líquidos influenciam a conta corrente (negativamente).

As Tabelas 10 e 11 apresentam as variáveis significativas para a dinâmica de curto prazo dos modelos ARDL e N-ARDL, além das estatísticas da variável de correção de erros (ECM) como suas respectivas estatísticas $t$ associadas. Para os modelos que levam em consideração o desalinhamento cambial, em média, registra-se uma velocidade para o modelo ARDL de $43 \%$ e, para o modelo N-ARDL, uma velocidade de 55\%. Em relação aos modelos que consideram a volatilidade do câmbio, a maior velocidade de ajuste média, entre os países, também consiste no modelo N-ARDL estimado, com cerca de 44\%. O modelo ARDL apresenta uma velocidade média de $41 \%$. Observando de forma discriminada por cada país, destaca-se a Índia, dado que, independentemente do modelo, o país é o que apresenta maior velocidade de ajuste. 
Tabela 10 - Correção de erro e variáveis significativas: dinâmica de curto prazo, modelos ARDL

\begin{tabular}{|c|c|c|c|c|c|}
\hline $\begin{array}{l}\text { País (ARDL } \\
\text { Model) }\end{array}$ & $\begin{array}{c}\text { Modelo } 1 \\
\text { Variáveis } \\
\text { Significativas }\end{array}$ & $\begin{array}{c}\text { ECM (-1) } \\
\text { (Prob.) }\end{array}$ & $\begin{array}{l}\text { País (ARDL } \\
\text { Model) }\end{array}$ & $\begin{array}{c}\text { Modelo } 2 \\
\text { Variáveis } \\
\text { Significativas }\end{array}$ & $\begin{array}{c}\text { ECM (-1) } \\
\text { (Prob.) }\end{array}$ \\
\hline \multirow{7}{*}{ Brasil } & BTC $(-1)$ & \multirow{7}{*}{$-0,48(0,00)$} & \multirow{7}{*}{ Brasil } & BTC $(-1)$ & \multirow{7}{*}{$0,62(0,00)$} \\
\hline & $\operatorname{TCREF}(-1,-2)$ & & & $\operatorname{TCREF}(-1,-2)$ & \\
\hline & DESAL(-1) & & & $\begin{array}{c}\text { VOLAT_TCREF } \\
(0)\end{array}$ & \\
\hline & $\operatorname{NFA}(-1)$ & & & $\operatorname{NFA}(-1)$ & \\
\hline & $\mathrm{XPIB}(0)$ & & & $\mathrm{XPIB}(0,-2)$ & \\
\hline & VOLAT_TT(-1,- & & & VOLAT_TT(-1,-- & \\
\hline & 2) & & & 2) & \\
\hline \multirow{5}{*}{ China } & BTC $(-2)$ & \multirow{5}{*}{$-0,39(0,00)$} & \multirow{5}{*}{ China } & BTC $(-1,-2)$ & \multirow{5}{*}{$-0,27(0,00)$} \\
\hline & $\operatorname{TCREF}(0)$ & & & $\mathrm{XPIB}(-1)$ & \\
\hline & $\operatorname{DESAL}(0)$ & & & $\operatorname{DESENF}(0)$ & \\
\hline & $\mathrm{XPIB}(-1)$ & & & \multirow{2}{*}{ VOLAT_TT (0) } & \\
\hline & $\operatorname{DESENF}(0)$ & & & & \\
\hline \multirow{3}{*}{ Índia } & NFA(0) & \multirow{3}{*}{$-0,61(0,00)$} & \multirow{3}{*}{ Índia } & NFA $(0)$ & \multirow{3}{*}{$-0,61(0,00)$} \\
\hline & $\mathrm{XPIB}(-2)$ & & & & \\
\hline & VOLAT_TT(0) & & & 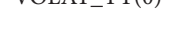 & \\
\hline \multirow{3}{*}{ Rússia } & $\operatorname{BTC}(-1,-2)$ & \multirow{3}{*}{$-0,27(0,00)$} & \multirow{3}{*}{ Rússia } & TCREF $(-1)$ & \multirow{3}{*}{$-0,41(0,00)$} \\
\hline & $\operatorname{TCREF}(0,-1)$ & & & & \\
\hline & $\operatorname{DESAL}(0,-1)$ & & & & \\
\hline \multirow{6}{*}{ África do Sul } & $\operatorname{BTC}(-1)$ & \multirow{6}{*}{$-0,42(0,00)$} & \multirow{6}{*}{ África do Sul } & $\operatorname{BTC}(-1)$ & \multirow{6}{*}{$-0,15(0,00)$} \\
\hline & $\operatorname{TCREF}(-1,-2)$ & & & TCREF (0) & \\
\hline & $\operatorname{DESAL}(0,-1,-2)$ & & & $\begin{array}{c}\text { VOLAT_TCREF } \\
(0)\end{array}$ & \\
\hline & $\operatorname{NFA}(-1)$ & & & XPIB (0) & \\
\hline & $\mathrm{XPIB}(0)$ & & & \multirow{2}{*}{ VOLAT_TT(0) } & \\
\hline & VOLAT_TT(0) & & & & \\
\hline \multicolumn{2}{|c|}{ Velocidade média ECM (-1) } & $-0,43$ & \multicolumn{2}{|c|}{ Velocidade média ECM (-1) } & $-0,41$ \\
\hline
\end{tabular}

Fonte: Elaboração própria. 
Tabela 11 - Correção de erro e variáveis significativas: dinâmica de curto prazo, modelo NARDL

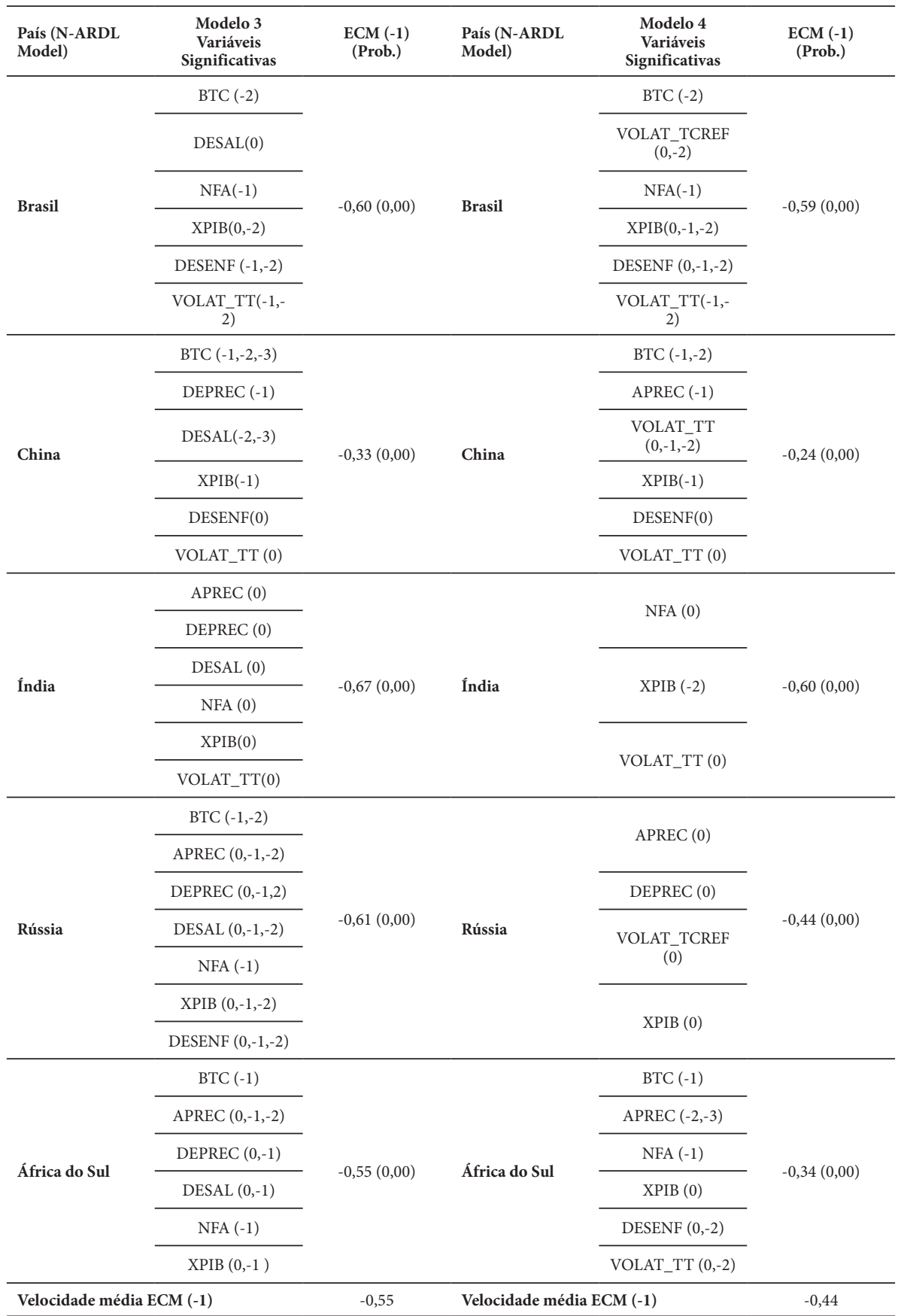

Fonte: Elaboração própria 
Cabe observarmos, ainda, as variáveis responsáveis pela determinação da conta corrente a partir da dinâmica de curto prazo. É possível constatar uma assimetria em relação às variáveis que se apresentaram relevantes no processo de ajustamento de longo prazo. No que se refere à abordagem ARDL, no modelo 1, a taxa de câmbio real efetiva e o desalinhamento se mostraram relevantes para todos os países, exceto para a Índia. Em relação ao modelo 2, taxa de câmbio e volatilidade só foram conjuntamente significativas para o Brasil e África do Sul. No que diz respeito à abordagem N-ARDL, para o modelo 3, o desalinhamento cambial aparece significativo para todas as economias emergentes. Em relação ao modelo 4, a volatilidade cambial só se apresenta para o ajustamento de curto prazo para Brasil e Rússia.

\section{CONSIDERAÇÕES FINAIS}

Este trabalho realizou uma investigação empírica acerca da conta de transações correntes a fim de verificar se a taxa de câmbio desempenhou um papel relevante no processo de ajuste externo. O período de estudo compreende os anos de 1998 a 2015 e a análise abrange o conjunto de economias emergentes pertencentes ao grupo BRICS (Brasil, Rússia, Índia, China e África do Sul). Foram estimados quatro modelos, dois lineares (ARDL) e outros dois não lineares (N-ARDL). O câmbio foi observado a partir de três conceitos: nível, desalinhamento e volatilidade.

Com base nos resultados obtidos, e com as limitações deste estudo, podemos verificar que a taxa de câmbio desempenha um papel importante para a promoção do ajuste externo apenas no curto prazo para Brasil, China, Rússia e África do Sul. Para o longo prazo, apesar de apresentar relação de cointegração, apenas para a Índia, em todos os modelos, a taxa de câmbio apresentou significância estatística.

Ressalta-se ainda a presença de uma forte assimetria entre quais variáveis macroeconômicas de controle apresentaram um papel importante no processo de ajuste externo para cada economia. Para o Brasil, as variáveis importantes na determinação do saldo da conta corrente consistiram nos ativos externos líquidos, grau de abertura e desenvolvimento financeiro. Para a China, apenas o grau de abertura se mostrou relevante para a determinação do saldo da conta corrente. Para a Índia, a taxa de câmbio, o desenvolvimento financeiro e a volatilidade dos termos de troca apresentaram significância. Para a Rússia, as variáveis relevantes consistiram no grau de abertura e no nível de desenvolvimento financeiro. Por fim, para a África do Sul, as variáveis importantes foram: apreciação, depreciação e desalinhamento cambial, grau de desenvolvimento financeiro, ativos externos líquidos e volatilidade dos termos de troca.

Finalmente, é possível tirar algumas lições deste estudo. A primeira consiste na confirmação que de fato existem questões econômicas específicas de cada membro 
dos BRICS, dado que o canal de ajustamento da conta corrente foi distinto para cada um dos países. A segunda questão versa sobre o mecanismo de ajustamento cambial. Esperava-se que nessas economias, ainda que em graus distintos, a taxa de câmbio em nível, a volatilidade ou o desalinhamento pudessem ter um papel corretivo no longo prazo, mas estas evidências são frágeis e não vigoram para todos os países dos BRICS.

Uma consideração final sobre as políticas econômicas relevantes para o ajuste externo das economias dos BRICS indica de forma mais ampla a necessidade de que estas economias emergentes evitem significativos e duradouros processos que sejam caracterizados por expressivas apreciações cambiais, desalinhamentos em grande magnitude e mesmo excessivas volatilidades da taxa de câmbio. $\mathrm{O}$ conjunto destes três aspectos referentes à taxa de câmbio tende a gerar um desempenho desfavorável sobre as transações correntes e, portanto, sobre o ajuste externo destas economias. A maior dificuldade para estas economias está associada a como lidar com choques externos, já que não têm controle sobre os mesmos, como foi o caso das políticas monetárias expansionistas com juros próximos de zero adotadas pelos EUA e Europa no imediato pós-crise financeira internacional de 2008, que resultou em significativas apreciações cambiais para as economias emergentes.

\section{REFERÊNCIAS}

ARON, J. et al. Exchange rate pass-through to import prices, and monetary policy in South Africa. The Journal of Development Studies, v. 50, n. 1, 2014.

BASHER, A; HAUG, A. A.; SADORSKY, P. The impact of oil shocks on exchange rates: a Markov-switching approach. Energy Economics, v. 54, p. 11-23, 2016.

BERNANKE, B. S. The global saving glut and the US current account deficit. The Federal Reserve Board, n. 77, 2005.

BIBOW, J. Global imbalances, the US dollar, and how the crisis at the core of global finance spread to "self-insuring" emerging market economies. Working Paper, Levy Economics Institute, n. 591, Mar. 2010.

BORIO, C. On the centrality of the current account in international economics. Journal of International Money and Finance, v. 68, p. 266-274, 2016.

BRESSER-PEREIRA, L. C. B. Macroeconomia da estagnação: crítica da ortodoxia convencional no Brasil pós-1994. São Paulo: Editora 34, 2007.

BRESSER-PEREIRA, L. C.; NAKANO, Y. Crescimento econômico com poupança externa? Revista de economia política, v. 23, n. 2, p. 3-27, 2003.

BRESSER-PEREIRA, L. C.; GALA, P. Por que a poupança externa não promove crescimento. Revista de Economia Política, v. 27, n. 1, p. 3-19, 2007. 
BRESSER-PEREIRA, L. C. O Brasil e o novo desenvolvimentismo. Interesse Nacional, p. 76-85, 2011.

BRESSER-PEREIRA, L.; OREIRO, J. L.; MARCONI, N. Macroeconomia desenvolvimentista: teoria e política econômica do novo desenvolvimentismo. Rio de Janeiro: Elsevier Brasil, 2017.

BRISSIMIS, S. N. et al. Current account determinants and external sustainability in periods of structural change. Economic Change and Restructuring, v. 45, n. 1-2, p. 71-95, 2012.

CARVALHO, F. J. C. Financial flows and the New Developmentalism. Revista de Economia Política, v. 38, n. 1(150), p. 115-124, 2018.

CALDERON, C. A.; CHONG, A.; LOAYZA, N. V. Determinants of current account deficits in developing countries. Contributions in Macroeconomics, v. 2, n. 1, 2002.

CHINN, M. D.; PRASAD, E. S. Medium-term determinants of current accounts in industrial and developing countries: an empirical exploration. Journal of International Economics, v. 59, n. 1, p. 47-76, 2003.

COUTO, S. V. V.; MEURER, R. Os impactos da política monetária na taxa de câmbio no Brasil: identificação via heterocedasticidade. Revista de Economia Contemporânea, v. 21, n. 2, p. $1-25,2017$.

DAS, S. China’s evolving exchange rate regime. IMF Working Paper, WP/19/50, 2019.

DOOLEY, M. P.; FOLKERTS-LANDAU, D.; GARBER, P. An essay on the revived Bretton Woods system. NBER Working Papers, National Bureau of Economic Research, n. 9971, 2003.

FLASSBECK, H. Exchange rate determination and the flaws of mainstream monetary theory. Revista de Economia Política, v. 38, n. 1(150), p. 99-114, 2018.

GHOSH, A. R.; OSTRY, J. D. The current account in developing countries: a perspective from the consumption-smoothing approach. The World Bank Economic Review, v. 9, n. 2, p. 305333, 1995.

GOURINCHAS, P. O. Global imbalances and global liquidity. In: ASIA ECONOMIC POLICY CONFERENCE, Federal Reserve Bank of San Francisco, San Francisco, California, Nov. 2012, p. 28-30.

GOURINCHAS, P. O.; REY, H. External adjustment, global imbalances, valuation effects. Handbook of International Economics, v. 4, p. 585-645, 2014.

GRUBER, J. W.; KAMIN, S. B. Explaining the global pattern of current account imbalances. Journal of International Money and Finance, v. 26, n. 4, p. 500-522, 2007.

ILZETZKI, E.; REINHART, C. M.; AND ROGOFF, K. S. Exchange Arrangements Entering the 21st Century: Which Anchor Will Hold? Quarterly Journal of Economics, v. 134, n. 2, p. 599646, 2019.

KREGEL, J. An alternative perspective on global imbalances and international reserve currencies. Jerome Levy Economics Institute of Bard College. Public Policy Brief, n. 116, 2010.

LANE, P. R.; MILESI-FERRETTI, G. M. External adjustment and the global crisis. Journal of International Economics, v. 88, n. 2, p. 252-265, 2012. 
LEE, J.; CHINN, M. D. Current account and real exchange rate dynamics in the G7 countries. Journal of International Money and Finance, v. 25, n. 2, p. 257-274, 2006.

MARTIN, F. E. Exchange rate regimes and current account adjustment: an empirical investigation. Journal of international Money and Finance, v. 65, p. 69-93, 2016.

MIRONOV, V. V.; PETRONEVICH, A. V. Discovering the signs of Dutch disease in Russia. Resources Policy, v. 46, part 2, p. 97-112, 2015.

NASSIF, A.; FEIJÓ, C.; ARAÚJO, E. Overvaluation trend of the Brazilian currency in the 2000s: empirical estimation. Revista de Economia Política, v. 35, n. 1 (138), p. 3-27, 2015.

OBSTFELD, M.; ROGOFF, K. S. Global current account imbalances and exchange rate adjustments. Brookings papers on economic activity, v. 1, p. 67-146, 2005.

PATTNAIK, R. K.; KAPUR, M.; DHAL, S. C. Exchange rate policy and management: the Indian experience. Economic and Political Weekly, v. 38, n. 22, p. 2139-2153, 2003.

PESARAN, M. H.; SHIN, Y. An autoregressive distributed-lag modelling approach to cointegration analysis. Econometric Society Monographs, v. 31, p. 371-413, 1998.

PESARAN, M. H.; SHIN, Y.; SMITH, R. J. Bounds testing approaches to the analysis of level relationships. Journal of applied econometrics, v. 16, n. 3, p. 289-326, 2001.

RODRIK, D. The real exchange rate and economic growth. Brookings Papers on Economic Activity, v. 2, p. 365-412, 2008.

SADIKU, L. et al. The persistence and determinants of current account deficit of FYROM: an empirical analysis. Procedia Economics and Finance, v. 33, p. 90-102, 2015.

SHIN, Y.; YU, B.; GREENWOOD-NIMMO, M. Modelling asymmetric cointegration and dynamic multipliers in a nonlinear ARDL framework. In: FESTSCHRIFT IN HONOR OF PETER SCHMIDT. Springer, New York, NY, p. 281-314, 2014.

VIEIRA, F. V.; MACDONALD, R. A panel data investigation of real exchange rate misalignment and growth. Estudos Econômicos, v. 42, p. 433-456, 2012. 


\section{APÊNDICE}

Tabela A1 - Regimes Cambiais - BRICS (1998 a 2015) Classificação Coarse

\begin{tabular}{lccccc}
\hline Ano / País & Brasil & China & Índia & Rússia & África do Sul \\
\hline 1998 & 2 & 1 & 2 & 6 & 3 \\
1999 & 5 & 1 & 2 & 5 & 3 \\
2000 & 3 & 1 & 2 & 2 & 3 \\
2001 & 3 & 1 & 2 & 2 & 3 \\
2002 & 3 & 1 & 2 & 2 & 3 \\
2003 & 3 & 1 & 2 & 3 \\
2004 & 3 & 1 & 2 & 3 \\
2005 & 3 & 1 & 2 & 2 & 3 \\
2006 & 3 & 2 & 2 & 2 & 3 \\
2007 & 3 & 2 & 2 & 2 & 3 \\
2008 & 3 & 2 & 2 & 3 & 3 \\
2009 & 3 & 2 & 3 & 3 & 3 \\
2010 & 3 & 2 & 3 & 3 & 3 \\
2011 & 3 & 2 & 3 & 3 \\
2012 & 3 & 2 & 2 & 3 \\
2013 & 3 & 2 & 2 & 3 \\
2014 & 3 & 2 & 2 & 3 \\
\hline
\end{tabular}

Nota: Classificação Coarse (1 a 6) Ilzetzki, Reinhart e Rogoff (2019).

1 e 2 correspondem a regimes fixo e rígido.

3 e 4 correspondem a regimes intermediários e administrados.

5 e 6 correspondem a regimes flexíveis (5) e mercados dual com mercado paralelo (6).

Fonte: Elaboração própria. 